\title{
UNIDADE DIDÁTICA DE ENSINO DOS PRIMEIROS SOCORROS PARA ESCOLARES: EFEITOS DO APRENDIZADO
}

\author{
Charles Wesley Alves Costa \\ Universidade Federal do Vale do São Francisco, Petrolina, Pernambuco, Brasil \\ Diego Luz Moura \\ Universidade Federal do Vale do São Francisco, Petrolina, Pernambuco, Brasil \\ Francisco Luís de Oliveira Costa \\ Universidade Federal do Vale do São Francisco, Petrolina, Pernambuco, Brasil \\ Roberta de Sousa Melo \\ Universidade Federal do Vale do São Francisco, Petrolina, Pernambuco, Brasil \\ Sérgio Rodrigues Moreira \\ Universidade Federal do Vale do São Francisco, Petrolina, Pernambuco, Brasil
}

\begin{abstract}
Resumo
O ensino do conteúdo Primeiros Socorros (PS) deve ser oportunizado na escola, uma vez que todo indivíduo poderá, em algum momento da vida, necessitar de tal conhecimento. O objetivo do estudo foi investigar o rendimento do aprendizado e sua retenção, sobre uma unidade didática de ensino do conteúdo PS para escolares. Foi aplicada uma unidade didática para 20 estudantes do Ensino Fundamental, divididos em dois grupos: 'Controle (C)' e 'PS'. A unidade didática contemplou o ensino da contenção de hemorragia, queimaduras e parada cardiorrespiratória. Foi adotado um método avaliativo padronizado para os conteúdos na pré-intervenção, e pós-intervenção - de cinco e a 45 dias. Ao contrário do C, o PS obteve resultados de aprendizado significativos aos cinco e aos 45 dias pós-intervenção $(p<0,05)$, diferindo estatisticamente do $C(p<0,05)$. Conclui-se que a unidade didática de ensino pode ser efetiva no aprendizado dos PS para escolares.
\end{abstract}

Palavras-chave: Primeiros Socorros. Aprendizagem. Retenção. Escolares.

\section{Introdução}

A história do atendimento de primeiros socorros pode ser lembrada pelos ensinamentos de médicos cirurgiões aos soldados que estavam em batalhas, para que estes realizassem condutas iniciais para socorrer militares feridos (MARKENSON et al., 2010). Tais condutas mostraram-se eficazes e realmente conseguiram diminuir a quantidade de combatentes mortos em batalhas. Esses 
procedimentos contemplavam condutas simples de contenção de hemorragias, reanimação cardiopulmonar, entre outras ações importantes para manter o suporte básico da vida (MARKENSON et al., 2010).

A expressão 'primeiros socorros' é usada para caracterizar uma série de procedimentos adotados com o fim de preservar vidas em risco iminente e em condições de urgência e emergência (CBMPR, 2013). Esses procedimentos geralmente são realizados por pessoas comuns, com conhecimento teórico e prático acerca das técnicas utilizadas. Os conhecimentos de primeiros socorros são escalonados de acordo com o nível de conhecimento na área, necessidade de emprego e maturidade dos educandos. Nesse caminho, especula-se que o conhecimento sobre primeiros socorros se faz necessário nas diferentes faixas etárias e para indivíduos de diferentes segmentos sociais e profissionais, pois o emprego desses procedimentos pode se fazer necessário para os mais variados grupos de uma população. Entretanto, apesar da explícita exposição sobre tal conteúdo, esse conhecimento ainda precisa ser ensinado e de fato absorvido pela população, visando a uma eficiente utilização quando necessário, nas diferentes situações de risco da vida diária e pelos diferentes grupos sociais envolvidos. Cabe salientar, portanto, a importância deste estudo, inclusive por abordar situações que fazem parte do cotidiano dos indivíduos envolvidos, colaborando, assim, com novos conhecimentos e informações significativas para a cultura do "prestar socorro".

Ademais, foi noticiado em programa televisivo de abrangência nacional no ano de 2013 (informação verbal) ${ }^{55}$, que uma criança com prévio treinamento em primeiros socorros, tornara-se "herói" ao salvar seu irmão em uma situação de urgência e necessidade de suporte à vida. Nesta mesma reportagem foi relatado que os Bombeiros do Estado de São Paulo possuíam um programa de instrução para prevenção de acidentes e procedimentos de emergência em escolas públicas do referido estado. Contudo, essa realidade não ocorre em todos os estados do País, com necessidade de criação de diversificados programas de treinamento aplicados por essas entidades competentes, ou mesmo formatação de unidades didáticas de ensino que viabilizem essa instrumentalização, visando à sua aplicação nos diversos segmentos da sociedade e entre as diferentes faixas etárias.

Em ambiente escolar, o conteúdo primeiros socorros costumeiramente é ministrado pelos professores de Educação Física. Em pesquisa realizada por Bernardes, Maciel \& Del Vecchio (2007), os professores de Educação Física apresentaram nível regular de capacitação em primeiros socorros, e não realizaram outra capacitação além da formação básica, tendo demonstrado deficiência em abordagens mais críticas, como, por exemplo, sobre o aspecto cardiopulmonar.

$\mathrm{Na}$ atualidade, diversos estudos na área dos primeiros socorros (GHIROTTO, 1998; SANTANA, 1999; PERGOLA, 2009; MAIA et al., 2012) foram realizados com foco apenas no conhecimento de professores sobre o conteúdo, e nenhum deles com direção a testagem e implementação de unidades didáticas de ensino-aprendizagem.

Na perspectiva desse problema, seria de grande importância o ensino deste conteúdo visando à transmissão eficiente de tal conhecimento a escolares, uma vez que estes podem ser agentes multiplicadores da cultura de socorrer da forma correta, sem causar danos secundários à vítima de um acidente inesperado (ALVAREZ \& CANETTI, 2007). Sendo assim, os objetivos do presente

55 Notícia transmitida pelo programa Fantástico, da Rede Globo de Televisão. Disponível em: <http://g1.globo.com/fantastico/noticia/2013/03/menino-vira-heroi-ao-salvar-irmao-apos-ter-aula-de-primeirossocorros.html>. Acesso em: 30 mar. 2013. 
estudo foram: 1) investigar os efeitos de rendimento do aprendizado de uma unidade didática de ensino do conteúdo 'primeiros socorros' em escolares do Ensino Fundamental; e, 2) verificar a retenção do conhecimento adquirido a partir da unidade didática de ensino aplicada.

\section{Materiais e Métodos}

\section{Amostra e Cuidados Éticos}

O estudo de caráter experimental com o grupo Controle foi realizado entre 20 alunos de ambos os sexos (13 Fem. e sete Masc.) do Ensino Fundamental do $8^{\circ}$ ano de escola do Estado da Bahia. A amostra foi selecionada por conveniência e dividida em dois grupos. As características gerais da amostra estão apresentadas na Tabela 1.

A pesquisa atendeu todos os procedimentos éticos norteadores da resolução 466/12 do Conselho Nacional de Saúde (CNS). A unidade escolar foi informada de todos os procedimentos realizados na pesquisa e assinou carta de anuência. Todos os responsáveis e participantes foram comunicados sobre os procedimentos éticos e assinaram o Termo de Consentimento Livre e Esclarecido. Destaca-se que, de igual modo, após término dos procedimentos experimentais da pesquisa, o grupo Controle também foi contemplado com a unidade didática de ensino dos primeiros socorros, atendendo assim os pressupostos éticos para grupo-controle, segundo a Resolução 466/12-CNS.

\section{Procedimentos}

A pesquisa foi realizada nas dependências de duas salas de aula do colégio participante. Para evitar o contato entre os alunos dos diferentes grupos, foram selecionados para o grupo Controle estudantes do turno vespertino e, para o grupo Primeiros Socorros, estudantes do turno matutino. A aplicação da unidade didática de ensino e das avaliações pré e pós-ensino- aprendizagem foram realizadas no contraturno dos escolares. Durante a aplicação da unidade didática de ensinoaprendizagem dos primeiros socorros foram ensinadas técnicas de contenção de hemorragias (HEMO), atendimento inicial a queimaduras (QUEIM) e procedimentos para suporte à vida durante a parada cardiorrespiratória (PCR).

Os procedimentos avaliativos da eficiência da unidade didática empregada foram aplicados por um avaliador externo convidado, o qual não tinha conhecimento da mesma e nem da divisão dos grupos. O mesmo avaliador, um oficial Capitão do Corpo de Bombeiros Militar de Pernambuco, também desconhecia quais alunos faziam parte do grupo Controle e do grupo Primeiros Socorros. O mesmo adotou os procedimentos avaliados de forma semelhante em HEMO, QUEIM e PCR para ambos os grupos. Cada aluno foi avaliado individualmente nos momentos pré- e pós-ensinoaprendizagem, cinco dias após o ensino ( $1^{\mathrm{a}}$ avaliação), com objetivo de verificar a eficiência da aplicação da unidade didática, e 45 dias após o ensino ( $2^{\mathrm{a}}$ avaliação), com o objetivo de verificar a retenção do conhecimento pelos escolares. 


\section{Unidade Didática de Ensino dos Primeiros Socorros}

A unidade didática contemplou o ensino dos conteúdos HEMO, QUEIM e PCR. Tais conteúdos foram trabalhados durante dois dias, com duração total de seis horas, através de exposição ilustrada e dialogada dos assuntos (documento suplementar). Também foram incluídas atividades práticas. $\mathrm{O}$ modelo de ensino adotado pelo instrutor priorizou informações do Manual Básico de Socorro de Emergência (ALVAREZ \& CANETTI, 2007). Em síntese, os conteúdos foram trabalhados a partir das seguintes diretrizes: 1. 'Chamar Socorro': números 190, 193 ou 192; 2. 'Hemorragia': biossegurança (uso de equipamentos de proteção individual), pressão direta no ferimento, elevação do membro lesado, ponto de pressão, curativo compressivo; 3. 'Queimaduras': usar água corrente, remover joias, evitar remédios caseiros (ex. ovo, creme dental, margarina, borra de café, etc.), não perfurar as bolhas, regra dos 9 (braço 9\%) e; 4. 'Parada Cardiorrespiratória': manter a vítima em decúbito dorsal, utilizar local rígido e plano, identificar pulso carotídeo, braços estendidos do socorrista durante a massagem cardíaca, 100 massagens cardíacas por minuto, sendo o protocolo para leigos sugerido por Markenson et al. (2010). Ao final de cada conteúdo, exemplos de fixação do conhecimento foram enfatizados na HEMO, QUEIM e no PCR.

A principal meta que a aplicação da unidade didática proposta busca atender é preparar o jovem escolar para uma eventual situação de emergência ou urgência, bem como capacitá-lo a atuar em circunstâncias que exijam um atendimento rápido, eficaz e capaz de salvar vidas.

No primeiro conteúdo, foram ensinados aos alunos o conceito e a classificação das hemorragias (internas, externas, arteriais e venosas). A partir disso, foram transmitidas informações sobre contenção das hemorragias. Tratou-se primeiramente da necessidade de utilizar "barreiras de proteção" durante o contato direto com sangue (biossegurança), sendo verificado o uso de luvas, óculos e máscara. No caso de não haver esses equipamentos de proteção individual (EPI), o jovem socorrista (JS) poderia adotar de "meio de fortuna" e improvisar utilizando, por exemplo, um saco plástico limpo. As formas de contenção de hemorragias ensinadas foram: Pressão Direta - quando o JS, utilizando barreiras de proteção, contém de forma direta e firme o local da hemorragia; Elevação do membro - quando o JS, utilizando barreiras de proteção, eleva o membro superior ou inferior onde está ocorrendo a hemorragia até uma altura superior à linha do coração, para que a gravidade ajude na contenção da mesma; Ponto de Pressão (Pressão Indireta) - quando o JS, utilizando barreiras de proteção, realiza a pressão na artéria braquial, no caso de hemorragia em membros superiores, ou a artéria femoral, no caso de hemorragia em membros inferiores, utilizando, por exemplo, uma mangueira de jardim que, ao ser pressionada, diminui significativamente o fluxo de água; e o Curativo Compressivo - quando o JS, utilizando barreiras de proteção, desenrola uma atadura limpa, de maneira firme no local da hemorragia, realizando pequena compressão, apenas para contê-la, e não para impedir totalmente o fluxo sanguíneo, fixando a parte final da atadura com esparadrapo ou realizando um 'nó simples'.

O segundo conteúdo trabalhado na unidade didática foi queimaduras, ocasião em que foram ensinadas aos alunos as classificações das queimaduras quanto à profundidade e quanto à extensão, sendo que no primeiro caso as queimaduras podem ser de primeiro grau - quando ocorre apenas dor e vermelhidão na pele de forma superficial; de segundo grau - quando além da dor local e vermelhidão ainda formam bolhas, de forma mais profunda; e de terceiro grau - quando existe dor, vermelhidão, formação de bolhas e ainda pode queimar mais profundamente os ossos, articulações e nervos. No segundo caso, a extensão da queimadura pode ser avaliada e medida seguindo a Regra 
dos 9 (ALVAREZ \& CANETTI, 2007). A partir da classificação das queimaduras, ocorreu a instrumentalização sobre o que fazer e não fazer em situações de atendimento quando inicialmente foi ensinado ao JS a utilizar água corrente para lavar o local afetado, bem como gerar sensação de alívio quanto ao aquecimento causado pela queimadura (queimadura por calor, queimaduras por frio, elétricas e químicas). Outro ponto importante foi a orientação sobre a necessidade de remoção imediata das joias que eventualmente a vítima estiver utilizando, especialmente nos dedos, pois assim evitam-se complicações por formação de edemas. Outro ponto abordado no conteúdo de queimaduras foi a atenção quanto aos remédios caseiros que deveriam ser evitados, tais como: aplicação de ovos, margarina, creme dental e até mesmo borra de café no momento e local em que ocorre a queimadura. Tais opções equivocadas poderiam provocar infecções no local da queimadura. Ademais, a ação de não perfurar as bolhas com alfinetes ou agulhas, mesmo que estéreis ou esterilizadas, já seria uma estratégia de segurança contra infecções locais.

O terceiro e último conteúdo ministrado na unidade didática dos primeiros socorros foi a parada cardiorrespiratória, onde os alunos foram orientados a verificar se a vítima respira e se tem pulso. Previamente, foi definido o conceito de parada cardíaca, além de terem sido dadas instruções sobre como identificá-la em jovens e adultos através do pulso carotídeo. Nesse momento, cada aluno localizou seu próprio pulso carotídeo e o de outro colega (prática em duplas). Salientou-se ainda que o local da verificação do pulso em bebês é o pulso braquial. A partir disso, seguiu-se com os procedimentos de como fazer uma massagem cardíaca eficiente, através dos seguintes passos: 1. Vítima posicionada em decúbito dorsal; 2. Sobre uma superfície plana e rígida; 3 . Identifica-se o pulso carotídeo; 4. Mantêm-se os braços estendidos; 5. Posiciona-se o "calcanhar da mão" do JS sobre o centro do peito da vítima, na linha dos mamilos; e, 6. Realizam-se 100 compressões por minuto, conforme protocolo para leigos (MARKENSON et al., 2010).

Durante a aplicação da unidade didática de ensino foi importante destacar que no adulto são utilizados os dois braços para realização das compressões cardíacas, que deve ter um comprimento de um terço da largura do tórax da vítima; no idoso e na criança utiliza-se apenas um braço; no caso do bebê, utilizam-se apenas dois dedos, sendo que o local de posicionamento dos dois dedos do JS seria a aproximadamente um dedo abaixo da linha dos mamilos da vítima. Para concluir, a aula foi conduzida com importantes informações de quando se deve encerrar o procedimento de salvamento em PCR. Tal condição ocorreria por: 1. Retorno da respiração espontânea (com uma parada não superior a 10 segundos para reavaliar a respiração e o pulso da vítima); 2 . Com a chegada de uma equipe de suporte avançado de vida; ou, 3. Quando a vítima for entregue aos cuidados médicos em um hospital ou posto de saúde. Outras informações também necessárias são as que definem quando não realizar o procedimento de salvamento em PCR, sendo: 1. Ao encontrar vítimas de calcinação (totalmente queimadas); 2. Em rigidez cadavérica (passado muito tempo da morte); 3. Em decapitação (com a cabeça separada do corpo); ou, 4. No caso mais importante, com a pessoa em boas condições de saúde, pois neste último caso, jovens (crianças e/ou adolescentes) ainda sem uma plena maturidade, poderiam entusiasmar-se pelos conteúdos aprendidos e tentarem aplicá-los em indivíduos próximos como irmãos, primos, colegas e vizinhos. Sendo assim, destacou-se que, numa condição de boa saúde, o coração funciona com estímulos elétricos, e que não seria saudável, anatomofisiologicamente, aplicar estímulos mecânicos neste órgão. Ao final de todo o conteúdo trabalhando, ainda foi realizada uma breve revisão geral, visando à fixação do conteúdo e à minimização de possíveis dúvidas sobre o assunto. 
Ademais, a assimilação desses novos saberes e de novas posturas para lidar com essas situações pode ser visto como algo positivo para a rotina dos escolares, além de estimular sua habilidade em transmitir seu aprendizado entre as pessoas próximas.

\section{Avaliação dos Conteúdos da Unidade Didática}

Para HEMO o avaliador mostrou um boneco com maquiagem de hemorragia em um dos membros superiores. Mostrou ainda os vários objetos que repousavam sobre a mesa, tais como: luva de procedimento, saco plástico limpo, atadura, gaze, esparadrapo, pano sujo e esponja de lavar pratos. Após visualização pelo JS o avaliador lhe indagou: "Esta criança caiu, cortou seu braço direito profundamente e está sangrando, como você pode ver. Você poderá utilizar qualquer desses itens ou nenhum deles. Como você agiria na contenção desta hemorragia?”. Para QUEIM o avaliador mostrou o outro membro superior do boneco com maquiagem de queimadura na região do braço e uma bolha decorrente de queimadura de segundo grau. Na cena (mesa) foi adaptada uma torneira para saída ilustrativa de água. No braço do boneco haviam joias (bijuteria), havia ainda na mesa borra de café, creme dental, ovos, margarina e alfinetes. Após visualização pelo JS o avaliador perguntou-lhe: "O que fazer em caso de queimadura e como sabemos ou calculamos quantos por cento do corpo foi afetado pela queimadura, lembrando que queimou apenas um dos membros superiores?". Na avaliação do conteúdo PCR, o avaliador deixou um boneco sentado numa cadeira e informou que ele possivelmente foi vítima de um infarto ou de uma parada cardíaca. Após visualização pelo JS, o avaliador questionou: "Como você sabe se a vítima teve uma parada cardíaca e o que você poderá fazer?’. O resultado esperado para os diferentes conteúdos consta no Quadro 1, sendo atribuído, para cada item correto, o valor de dois pontos, e para cada item incorreto, o valor de zero pontos. A somatória de cada conteúdo no quadro poderá chegar ao valor de 10 pontos, e ao final é atribuída a média das notas dos três conteúdos.

\begin{tabular}{|l|l|c|}
\hline Conteúdo & Procedimentos & Pontos \\
\hline A. Hemorragia (HEMO) & $\begin{array}{l}\text { 1. Biossegurança; 2. Pressão Direta; 3. Elevação do membro; 4. Ponto de } \\
\text { Pressão; 5. Curativo Compressivo. }\end{array}$ & \\
\hline B. Queimadura (QUEIM) & $\begin{array}{l}\text { 1. Uso de água corrente; 2. Remover jóias; 3. Evitar remédios caseiros; 4. Não } \\
\text { furar bolhas; 5. Regra dos 9 (superfície). }\end{array}$ & \\
\hline $\begin{array}{l}\text { C. Parada } \\
\text { Cardiorrespiratória (PCR) }\end{array}$ & $\begin{array}{l}\text { 1. Vítima em decúbito dorsal; 2. Local rígido e plano; 3. Identificar Pulso } \\
\text { Carotídeo; 4. Braços estendidos na massagem; 5. Compressões 100/min. }\end{array}$ & \\
\hline Total & Média dos três conteúdos. & \\
\hline
\end{tabular}

Quadro 1. Modelo de avaliação nos conteúdos Hemorragia

(A), Queimadura (B) e Parada Cardiorrespiratória (C).

Após avaliação dos conteúdos de primeiros socorros adotados no presente estudo para ambos os grupos (Controle e Primeiros Socorros) nos momentos pré- e pós-ensino-aprendizagem ( $1^{\mathrm{a}}$ avaliação: cinco dias após a intervenção, e $2^{\mathrm{a}}$ avaliação: 45 dias após a intervenção, apenas para o grupo Primeiros Socorros), os resultados foram tabulados em planilha eletrônica para cálculo das médias dos resultados obtidos para cada conteúdo de ensino, bem como das médias do conteúdo total trabalhado na unidade didática de ensino dos primeiros socorros. 


\section{Análise Estatística}

A normalidade dos dados foi testada pelo Shapiro-Wilk test. A análise dos dados foi realizada a partir de estatística descritiva com medidas de tendência central (média), dispersão (desvio padrão) e frequências percentuais. Teste $t$ de Student pareado e não paramétrico (Wilcoxon matched pairs test) dentro do grupo Controle (Pré $v s$. Pós ${ }^{1}$ ), e teste $t$ de Student para amostras independentes, comparando o pré-teste entre grupos (Mann-Whitney test) foram adotados. Análise de variância ANOVA para medidas repetidas com Post Hoc de Dunn — Friedman test (para dados não paramétricos), que detectou as possíveis diferenças dentro do grupo Primeiros Socorros (Pré vs. Pós $^{1}$ vs. Pós ${ }^{2}$ ). Além disso, uma ANOVA ordinária com Post Hoc de Dunn - Kruskal-Wallis test (para dados não paramétricos) evidenciou as possíveis diferenças das variações percentuais do pré para o pós-treinamento entre os grupos Controle e Primeiros Socorros. O nível de significância adotado no estudo foi p<0,05 e o software utilizado foi o GraphPad InStat (versão 3.0).

\section{Resultados}

A Tabela 1 apresenta as características antropométricas da amostra de escolares para o grupo Controle, o qual não recebeu o ensino através da unidade didática, e para o grupo Primeiros Socorros, o qual recebeu a intervenção da unidade didática. Constata-se que ambos os grupos não diferem nas características gerais apresentadas ( $p>0,05)$, o que, nesses aspectos, deixa-os pareados para posteriores comparações.

\begin{tabular}{|c|c|c|c|}
\hline & Controle & $\begin{array}{l}\text { Primeiros } \\
\text { Socorros }\end{array}$ & $p$ \\
\hline Amostra (n) & 10 & 10 & - \\
\hline Idade (anos) & $12,9 \pm 0,6$ & $13,0 \pm 0,5$ & 0,673 \\
\hline Peso (Kg) & $54,3 \pm 14,3$ & $58,7 \pm 18,9$ & 0,564 \\
\hline Estatura (cm) & $162,0 \pm 7,0$ & $163,0 \pm 8,0$ & 0,725 \\
\hline $\operatorname{IMC}\left(\mathrm{Kg}_{\mathrm{g}} \mathrm{m}^{2(-1)}\right)$ & $20,5 \pm 3,9$ & $21,7 \pm 4,9$ & 0,554 \\
\hline
\end{tabular}

IMC: Índice de Massa Corporal.

Tabela 1. Características gerais dos participantes dos grupos Controle e Primeiros Socorros.

A Tabela 2 apresenta a comparação, no grupo Controle e grupo Primeiros Socorros, das condições pré e pós-ensino-aprendizagem de primeiros socorros. Evidenciou-se que, ao contrário do grupo Controle, o grupo que recebeu a intervenção com a unidade didática de ensino dos primeiros socorros obteve resultados estatisticamente superiores de rendimento de aprendizado na Avaliação 1, aos cinco dias após o ensino (Pós ${ }^{1}$ ), e na Avaliação 2 aos 45 dias após o ensino (Pós ${ }^{2}$ ), nos componentes queimadura (QUEIM) e reanimação por parada cardiorrespiratória (PCR), bem como na média total de todos os componentes avaliados $(\mathrm{p}<0,05)$. Para o conteúdo HEMO, quando comparado a condição pré-avaliação, ocorreu aumento do rendimento de aprendizado $(\mathrm{p}<0,01)$ na Avaliação 1 aos cinco dias após o ensino (Pós ${ }^{1}$ ), sem aumento significativo na Avaliação 2 aos 45 
dias após o ensino $\left(\mathrm{Pós}^{2}\right)$, contudo, o resultado obtido no momento Pós ${ }^{2}$ não diferiu do momento Pós $^{1}(\mathrm{p}>0,05)$.

\begin{tabular}{|c|c|c|c|c|c|}
\hline & \multicolumn{2}{|c|}{ Controle $(n=10)$} & \multicolumn{3}{|c|}{ Primeiros Socorros $(n=10)$} \\
\hline & Pré & Pós ${ }^{1}$ & Pré & Pós ${ }^{1}$ & Pós ${ }^{2}$ \\
\hline HEMO & $1,80 \pm 0,63$ & $1,80 \pm 0,63$ & $1,40 \pm 1,35$ & $9,40 \pm 1,00^{*}$ & $5,60 \pm 1,84$ \\
\hline QUEIM & $1,20 \pm 1,03$ & $1,40 \pm 1,35$ & $1,20 \pm 1,40$ & $9,20 \pm 1,00^{*}$ & $8,00 \pm 2,11^{*}$ \\
\hline PCR & $0,20 \pm 0,63$ & $0,60 \pm 1,35$ & $1,20 \pm 1,93$ & $9,60 \pm 0,80^{*}$ & $9,20 \pm 1,93^{*}$ \\
\hline TOTAL & $1,07 \pm 0,47$ & $1,27 \pm 0,49$ & $1,27 \pm 1,24$ & $9,40 \pm 0,66^{*}$ & $7,60 \pm 1,48 * *$ \\
\hline
\end{tabular}

HEMO: Conteúdo hemorragia; QUEIM: Conteúdo queimadura; PCR: Conteúdo parada cardiorrespiratória; TOTAL: Média de todo conteúdo pedagógico trabalhado; Pós ${ }^{1-2}: 1^{\mathrm{a}}$ e $2^{\mathrm{a}}$ avaliação no momento pós-intervenção. ${ }^{*} \mathrm{p}<0,01$ em relação ao Pré no mesmo grupo; $* *$ p $<0,05$ em relação ao Pré no mesmo grupo; $\uparrow \mathrm{p}<0,05$ em relação ao Pós ${ }^{1}$ no mesmo grupo.

Tabela 2. Média $( \pm \mathrm{DP})$ do rendimento escolar no conteúdo primeiros socorros pré-ensinoaprendizagem (Pré) e pós-ensino aprendizagem (Pós ${ }^{1-2}$ ) nos grupos Controle e Primeiros Socorros.

A Figura 1 apresenta a variação percentual do rendimento nos conteúdos de primeiros socorros, considerando o resultado da condição pós-ensino-aprendizagem menos a condição préensino-aprendizagem para o grupo Controle e grupo Primeiros Socorros. Verifica-se que ocorreram aumentos entre 80 e $84 \%$ no aprendizado do grupo Primeiros Socorros na $1^{\text {a }}$ avaliação após aplicação da unidade didática de ensino (cinco dias após o ensino) e aumentos entre 42 e $80 \%$ no aprendizado ao se considerar a $2^{\mathrm{a}}$ avaliação após aplicação da unidade didática de ensino (45 dias após o ensino). Ao considerar o rendimento total do aprendizado de primeiros socorros neste grupo, ocorreram aumentos de 81,3\% (cinco dias após o ensino) e 63,3\% (45 dias após o ensino), sendo esses valores estatisticamente significantes $(\mathrm{p}<0,01)$ quando comparados ao grupo Controle, o qual obteve aumentos não significantes entre 0 e $4 \%$ ( $>>0,05)$.

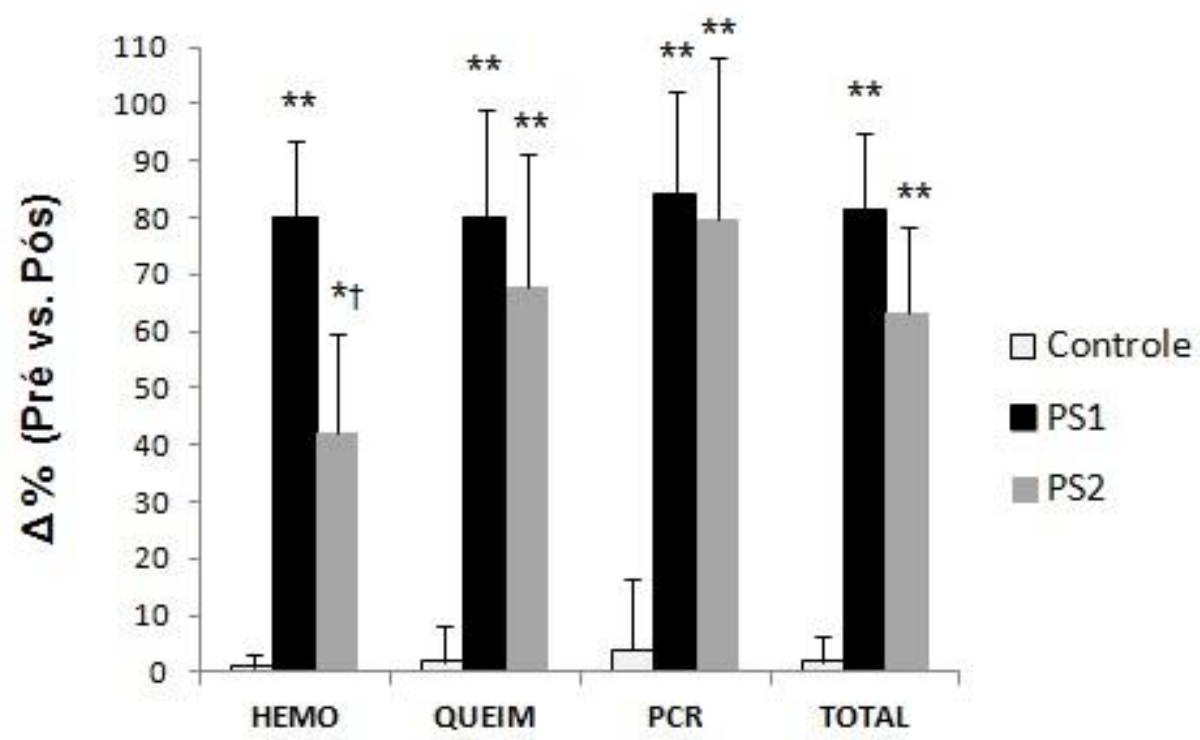

Figura 1. Média $( \pm \mathrm{DP})$ da variação percentual $(\Delta \%)$ do rendimento pósensino-aprendizagem para o rendimento pré-ensino-aprendizagem nos 
grupos Controle $(n=10)$ e Primeiros Socorros $(n=10)$ na $1^{a}(P S 1)$ e $2^{a}$ avaliação (PS2). HEMO: Conteúdo hemorragia; QUEIM: Conteúdo queimadura; PCR: Conteúdo parada cardiorrespiratória; TOTAL: Média de todo conteúdo pedagógico trabalhado. $* * p<0,01$ em relação ao grupo Controle dentro de cada conteúdo; *p<0,05 em relação ao PS1 no conteúdo HEMO; $\uparrow \mathrm{p}<0,05$ em relação ao grupo Controle no conteúdo HEMO.

\section{Discussão}

Os principais achados do presente estudo indicaram que a unidade didática de ensinoaprendizagem do conteúdo primeiros socorros repercutiu em um significativo rendimento de aprendizado dos conteúdos HEMO, QUEIM e PCR em escolares do Ensino Fundamental. Além disso, com exceção do conteúdo HEMO, ocorreu retenção do conhecimento para os conteúdos QUEIM, PCR e conteúdo total quando a amostra foi novamente avaliada 45 dias após a aplicação da unidade didática (Tabela 2 e Figura 1). Embora os escolares não tenham retido o conhecimento do conteúdo HEMO aos 45 dias após realização da unidade didática de ensino, os resultados ainda se mostraram significantemente superiores quando comparados ao grupo Controle (Figura 1). O grupo Primeiros Socorros aumentou em cerca de 80 e $84 \%$ o aprendizado nos diferentes conteúdos abordados (contenção de hemorragia, queimadura e parada cardiorrespiratória) na $1^{\text {a }}$ avaliação após aplicação da unidade didática, cinco dias pós-ensino, e aumentou entre 42 e $80 \%$ no aprendizado ao se considerar a $2^{\mathrm{a}}$ avaliação após aplicação da unidade didática, 45 dias pós-ensino. Ao considerar o rendimento total do aprendizado de primeiros socorros neste grupo, ocorreram aumentos de 81,3\% ( $1^{\mathrm{a}}$ avaliação) e $63,3 \%$ ( $\mathrm{a}^{\mathrm{a}}$ avaliação), sendo esses valores estatisticamente superiores $(\mathrm{p}<0,01)$ quando comparados ao grupo Controle, o qual obteve aumentos não significantes entre 0 e $4 \%$ (Figura 1).

Alguns autores têm verificado a importância e/ou o conhecimento de profissionais da área da saúde sobre os conteúdos de primeiros socorros (GHIROTTO, 1998; SANTANA, 1999; PERGOLA, 2009; MAIA et al., 2012). Entretanto, ainda existe uma carência de informações quanto à proposição de unidades didáticas de ensino e aprendizagem direcionadas a escolares, o que foi proposto neste trabalho. Em nosso conhecimento, esse é o primeiro estudo, com grupo-controle e avaliação cega a investigar a efetividade e a retenção do conhecimento com a aplicação de uma unidade didática de ensino e aprendizagem de primeiros socorros em adolescentes escolares do Ensino Fundamental.

A partir da unidade didática para o ensino do conteúdo primeiros socorros proposto no presente estudo para escolares adolescentes do Ensino Fundamental, a qual demonstrou sua efetividade no ensino-aprendizagem desse assunto, espera-se contribuir para a orientação de profissionais da saúde que visam à formação de jovens (crianças e adolescentes) mais preparados para cuidar da saúde e integridade da vida do próximo em situação de urgência e/ou emergência durante um acidente e/ou condição de risco de vida iminente. Além da possível atuação desse escolar em uma situação real de atendimento de primeiros socorros, poderão promover a multiplicação dos conhecimentos, tanto a seus pares como a seus familiares e cidadãos em comum na sociedade. Além disso, passará a melhor compreender o processo saúde-doença e vida-morte, o 
que naturalmente possibilitará o maior cuidado e preocupação com a qualidade de vida da população.

Uma limitação do presente estudo foi não ter investigado uma unidade didática tradicional de ensino dos primeiros socorros, como por exemplo, o ensino que vem sendo realizado sobre esse assunto nas escolas. Tal limitação se justifica pela dificuldade de se verificar a sistematização desse conteúdo, já que o assunto fica resumido a comentários diluídos em diferentes disciplinas da escola.

Nesse sentido, pensando numa aplicação prática, torna-se necessário que se construa um aparato legal que garanta a inserção dos conteúdos de primeiros socorros na escola, com um aspecto mais formal e ajustando-os à carga horária escolar, para assim se estabelecer uma relação de ensino e aprendizagem que valorize a metodologia didática de aplicação do conteúdo e, sobretudo, sua avaliação.

\title{
Considerações Finais
}

Conclui-se que a unidade didática de ensino-aprendizagem do conteúdo primeiros socorros pode ser efetiva no rendimento de aprendizagem em adolescentes escolares do Ensino Fundamental. Em adicional, com exceção do conteúdo hemorragia, ocorreu retenção do conhecimento no grupo experimental de primeiros socorros 45 dias após o ensino. Sugere-se mais estudos investigando novas metodologias de ensino dos primeiros socorros para escolares do Ensino Fundamental, especialmente para o conteúdo hemorragia, o qual a retenção do conhecimento não foi satisfatória, bem como propondo metodologias para escolares de faixas etárias diferentes às estudadas na presente pesquisa.

\section{TRAINING UNIT OF TEACHING FIRST AID FOR SCHOOL CHILDREN: THE EFFECTS OF LEARNING}

\begin{abstract}
The teaching of first aid (FA) should be provided in school, since everyone may at some point in life require such knowledge. The objective of this study was to investigate the efficiency of learning and its retention on a teaching unit of FA content for schoolchildren. Teachers applied a teaching unit for 20 elementary school students, divided into Control (C) and FA groups. The teaching unit included the teaching of bleeding containment, burns, and cardiopulmonary arrest. Researchers adopted a standardized evaluation method to the contents in the pre-intervention, at 5 and 45 days post-intervention. Unlike $C$, the FA group had significant learning outcomes at 5 and 45 days postintervention $(\mathrm{p}<0.05)$, differing statistically from the $\mathrm{C}$ group $(\mathrm{p}<0.05)$. We concluded that the teaching unit can be effective for school children in FA learning.
\end{abstract}

Keywords: First Aid. Learning. Retention. School. 


\title{
UNIDAD DIDÁCTICA DE ENSEÑANZA DE LOS PRIMEROS AUXILIOS PARA ESCOLARES: EFECTOS DEL APRENDIZAJE
}

\begin{abstract}
Resumen
La enseñanza de contenidos de Primeros Auxilios (PA) debe proporcionarse en la escuela, ya que cualquier persona podrá, en algún momento de la vida, necesita de dichos conocimientos. El objetivo del estudio fue investigar el rendimiento del aprendizaje y su retención en una unidad didáctica de contenido del PA para escolares. Fue aplicada una unidad didáctica para 20 estudiantes de la Enseñanza Fundamental, divididos en dos grupos: 'Controle (C)' y 'PA'. La unidad didáctica contempló la enseñanza de la contención de hemorragia, quemaduras y parada cardiorrespiratoria. Fue adoptado un método evaluativo estandarizado para los contenidos en la pre-intervención y posintervención de 5 a 45 días. A lo contrario del $C$, el $P A$ obtuve resultados de aprendizaje significativos a los 5 y 45 días pos-intervención (p<0,05), difiriendo estadísticamente del $C$ $(\mathrm{p}<0,05)$. La conclusión es que la unidad didáctica de enseñanza puede ser efectiva en el aprendizaje de los PA para escolares.
\end{abstract}

Palabras-clave: Primeros Auxilios. Aprendizaje. Retención. Escolares.

\section{Referências}

ALVAREZ, F. S.; CANETTI, M. D. Manual básico de socorro de emergência para técnicos em emergências médicas e socorristas. 2. ed. São Paulo: Editora Atheneu, 2007.

BERNARDES, E. L.; MACIEL, F. A.; DEL VECCHIO, F. B. Primeiros socorros na escola: nível de conhecimento dos professores da cidade de Monte Mor. Revista Movimento e Percepção, Espírito Santo do Pinhal, v. 8, n. 11, jul.-dez., 2007.

CORPO DE BOMBEIROS MILITAR DO ESTADO DO PARANÁ - CBMPR. Primeiros Socorros. Curitiba-PR. Disponível em: <http://www.bombeiros.pr.gov.br/modules/conteudo/conteudo.php?conteudo=87>. Acesso em: 30 mar. 2013.

GHIROTTO, F. M. S. Socorros de urgência e a preparação do profissional de Educação Física. 1998. Tese (Doutorado em Educação Física) - Pós-Graduação em Educação Física, Faculdade de Educação Física, UNICAMP, Campinas, 1998.

MAIA, M. F. M. et al. Primeiros socorros nas aulas de educação física nas escolas municipais de uma cidade no norte do Estado de Minas Gerais. Coleção Pesquisa em Educação Física, v. 11, n. 1, p. 195-204, abr. 2012.

MARKENSON, D. et al. Part 17: First Aid: 2010 American Heart Association and American Red Cross Guidelines for First Aid. Circulation, Dallas, v. 2, n. 122 (18 Suppl. 3), p. S934-S946, 2 nov. 2010. 
PERGOLA, A. M. Capacitação obrigatória em primeiros socorros. 2009. Dissertação (Mestrado em Enfermagem) — Faculdade de Ciências Médicas, UNICAMP, Campinas, 2009.

SANTANA, V. H. Resgate, salvamento aquático e a inclusão de informações preventivas e de sobrevivência pertinentes às aulas de natação dos clubes de Campinas. 1999. $49 \mathrm{f}$. Trabalho de conclusão de curso (Treinamento em Esportes) — Faculdade de Educação Física, UNICAMP, Campinas, 1999.

Recebido em: 03/06/2014

Revisado em: 03/11/2014

Aprovado em: 17/12/2014

Endereço para Correspondência:

Sérgio Rodrigues Moreira

serginhocapo@gmail.com

Colegiado de Educação Física (CEFIS)

Universidade Federal do Vale do São Francisco (UNIVASF), Pernambuco, Brasil

Av. José de Sá Maniçoba, s/n — Centro - CEP: 56 304-917 — Petrolina-PE, Brasil 